\title{
Manajemen dan Rekayasa Lalu Lintas pada Jalan Bunga Raya-Raden Patah Kota Batam
}

\author{
Puput Famela Rahayu, Novita Sari, Nomin \\ Dinas Perhubungan Kabupaten Anambas \\ Politeknik Transportasi Darat Indonesia - STTD \\ Politeknik Transportasi Darat Indonesia - STTD \\ Email: novita.s@ptdisttd.ac.id
}

\begin{abstract}
Abstrak
Ruas jalan Bunga Raya-Raden Patah merupakan jalan yang menghubungkan antara pusat-pusat kegiatan utama perkantoran dan perdagangan yang berada di Kota Batam. Ruas jalan tersebut juga merupakan jalan satu-satunya yang menghubungkan dua pusat kegiatan utama di Kota Batam sehingga akan berdampak pada kinerja lalu lintas. Dengan adanya masalah ini perlu adanya pengkajian ulang untuk meningkatkan kinerja lalu lintas di ruas Bunga RayaRaden Patah Kota Batam. Penelitian ini bertujuan untuk meningkatkan kinerja lalu lintas (ruas, simpang dan jaringan) dan merumuskan konsep Manajemen dan Rekayasa Lalu Lintas di daerah lintas pada Jalan Bunga Raya-Raden Patah Kota Batam. Metode penelitian yang digunakan adalah dengan menganalisa pembebanan jaringan pada sistem jaringan jalan di wilayah studi dengan menggunakan bantuan software Vissim. Hasil penelitian menunjukkan bahwa kinerja lalu lintas pada Jalan Bunga RayaRaden Patah Kota Batam memiliki nilai tundaan rata-rata 109 detik, dengan kecepatan jaringan $37 \mathrm{~km} / \mathrm{jam}$, total jarak perjalanan 12,90 km dan total waktu yang dibutuhkan 1.254 detik. Setelah dilakukan usulan penanganan Manajemen dan Rekayasa Lalu lintas dalam mengatasi permasalahan lalu lintas tersebut terdapat 2 rekomendasi penangananan yang dilakukan yaitu; 1) melakukan peningkatan kapasitas ruas dan memperbaiki waktu apill di simpang indomobil dan simpang baloi; dan 2) melakukan peningkatan ruas, memperbaiki waktu apill di simpang indomobil dan simpang baloi, menutup fasilitas putar balik arah di ruas yos sudarso 1 dan bunga raya 1, melakukan perekayasaan simpang prioritas di simpang polsek lubuk baja dengan membuka median pada ruas bunga raya 1 serta merubah fase apill di simpang baloi.
\end{abstract}

Kata Kunci: Jaringan Jalan, Manajemen dan Rekayasa Lalu Lintas, Kinerja lalu lintas, Pembebanan Jaringan.

\begin{abstract}
The Bunga Raya-Raden Patah road section is a road that connects the main centers of office and trade activities in Batam City. This road section is also the only road that connects the two main activity centers in Batam City so that it will have an impact on traffic performance. With this problem, it is necessary to reassess to improve traffic performance on the Bunga RayaRaden Patah section of Batam City. This study aims to improve traffic performance (sections, intersections and networks) and formulate the concept
\end{abstract}


of Traffic Management and Engineering in traffic areas on Jalan Bunga Raya-Raden Patah Batam City. The research method used is to analyze the network loading on the road network system in the study area using the Vissim software. The results show that traffic performance on Jalan Bunga RayaRaden Patah Batam City has an average delay value of 109 seconds, with a network speed of $37 \mathrm{~km} / \mathrm{hour}$, a total travel distance of $12.90 \mathrm{~km}$ and a total time required of 1,254 seconds. After the proposed handling of Traffic Management and Engineering in overcoming the traffic problem, there are 2 recommendations for handling, namely; 1) increase the segment capacity and improve the apill time at the indomobil and baloi intersections; and 2) improve the section, improve the apill time at the Indomobil intersection and the Baloi intersection, close the back and forth facilities at the Yos Sudarso 1 and Bunga Raya 1 sections, engineer the priority intersection at the Lubuk Baja Police intersection by opening the median on the Bunga Raya 1 section and change the apill phase at the baloi intersection.

Keywords: Road Network, Traffic Management and Engineering, Traffic Performance, Network Loading.

\section{A. PENDAHULUAN}

Suatu kota tersusun beberapa sistem, yaitu sistem aktivitas kota, sistem pengembangan lahan dan sistem lingkungan, sehingga suatu kawasan perkotaan tidak akan berada dalam keadaan yang stagnan dan statis, tetapi segenap komponennya baik fisik maupun non fisik akan selalu berada dalam keadaan yang dinamis (Nurmandi, 2003). Salah satu fungsi dari kawasan perkotaan adalah sebagai pusat koleksi dan distribusi pelayanan barang dan jasa dalam bentuk sarana dan prasarana pergantian moda transportasi. Menurut Tamin, 1997, lalu lintas dipengaruhi oleh adanya tata guna lahan. Suatu perjalanan disebabkan karena perbedaan tata guna lahan. Dalam memenuhi kebutuhan hidupnya, setiap individu bergerak dari tata guna lahan tertentu ke tata guna lahan lainnya.

Salah satu jenis tata guna lahan yang memiliki pengaruh cukup besar terhadap pergerakan lalu lintas adalah perdagangan (pasar dan ruko). Dengan meningkatnya perkembangan akitvitas (pusat-pusat kegiatan) telah meningkatkan bangkitan pergerakan yang cenderung mengakibatkan konflik terhadap lalu lintas yang berada di sekitarnya. Adanya bangkitan dan tarikan perjalanan oleh tata guna lahan perdagangan tersebut membutuhkan dukungan kinerja sarana dan prasarana transportasi, berupa angkutan umum, ruas dan simpang jalan, areal perparkiran, fasilitas pejalan kaki, halte, terminal dan sebaginya. Tanpa adanya dukungan sarana dan prasarana transportasi, dipastikan akan terjadi ketidakseimbangan antara permintaan dan penawaran perjalanan, yang pada akhirnya akan menimbulkan berbagai permasalahan lalu lintas.

Sebagai kota terencana, Batam merupakan salah satu kota dengan pertumbuhan terpesat di Indonesia, ketika dibangun pada tahun 1970-an oleh Otorita Batam (saat ini bernama BP Batam) kota ini hanya dihuni sekitar 6.000 penduduk dan dalam tempo 40 tahun penduduk Batam bertumbuh hingga 158 kali lipat (Sumber: Wikipedia). Kota Batam terdapat dua Kawasan CBD yaitu: Batam Center dan Nagoya. Kawasan CBD tersebut merupakan daerah tarikan yang paling besar dan masing-masing memiliki peranan yang berbeda. Batam Center dijadikan sebagai pusat perkantoran sedangkan Nagoya sebagai pusat perdagangan di Kota Batam. Nagoya dipilih oleh peneliti karena tarikan perjalanan yang dihasilkan cukup besar yaitu 202.747 perjalanan orang/hari yang didapat dari Pola Umum Kota Batam 2019 dan pusat perdagangan (salah satu penggerak perekonomian Kota Batam). Sektor penggerak perekonomian di Kota Batam meliputi sektor industri (minyak dan gas, elektronik, perkalapan 
dan tambang) dan sektor perdagangan, sehingga banyak pusat pertokoan yang mendominasi di Kota Batam. Maka dari itu, berdasarkan PP No 46 tahun 2007 sebagaimana telah diubah terakhir dengan PP No 62 tahun 2019 bahwa Kota Batam dijadikan sebagai kawasan perdagangan bebas dan pelabuhan bebas yang menjadikan semua barang elektronik dan kendaraan dibebaskan dari PPN, serta menyebabkan barang elektronik dan mobil yang akan keluar dari Batam akan dikenakan pajak tambahan.

Keberadaan Nagoya sebagai pusat perbelanjaan, jasa dan perdagangan elektronik Kota Batam menarik masyarakat untuk melakukan kegiatan perdagangan. Nagoya terletak di Kecamatan Lubuk Baja yang berada di ruas Jalan Imam Bonjol dan Teuku Umar. Namun untuk memasuki kawasan tersebut dari CBD 1 ke CBD 2 hanya dihubungkan oleh ruas Jalan Bunga Raya-Raden Patah. Di sekitar ruas jalan tersebut terdapat beberapa perkantoran, ruko, perumahan serta sekolah yang beroperasi di pagi hari hingga sore hari sehingga aktivitas di ruas ini ramai. Keadaan tersebut mengakibatkan kendaraan keluar masuk dari pertokoan sehingga mengurangi kecepatan pengendara yang lain. Selain itu angkutan umum juga menurunkan/menaikan penumpang tidak pada tempatnya sehingga mengurangi kapasitas jalan. Ruas jalan tersebut membentuk 2 persimpangan yaitu simpang indomobil dan simpang baloi.

Kinerja Ruas jalan yang dihasilkan cukup rendah. Ruas Jalan Raden Patah memiliki kinerja ruas yang cukup rendah dengan V/C Ratio 0,46 dan kecepatan 46,88 km/jam. Sedangkan ruas Jalan Bunga Raya 1 memiliki V/C Ratio 0,69 dengan rata-rata kecepatan 30,31 $\mathrm{km} / \mathrm{jam}$ sehingga pertemuan 2 ruas tersebut mengakibatkan antrian di simpang indomobil dan simpang baloi (Pola Umum Kota Batam 2019). Tingginya kegiatan di kawasan Nagoya dan banyaknya pengendara yang melewati ruas jalan tersebut mengakibatkan antrian di simpang indomobil. Selain itu, Tipe jaringan jalan di Kota Batam adalah linier sehingga pembebanan lalu lintas pada ruas jalan tersebut sangat tinggi dan Jalan Bunga Raya merupakan jalan arteri yang digunakan sebagai jalur penghubung dari CBD 1 ke CBD 2.

Berdasarkan Rancangan Pembangunan Jangka Menengah Daerah (RPJMD) Kota Batam, untuk tercapainya tujuan menyediakan infrastrukur kota yang berkualitas mengatasi masalah perkotaan dengan melakukan peningkatan dan pengembangan kapasitas dan kualitas jaringan jalan serta pengaturan alur lintas jaringan jalan melalui pembangunan, peningkatan, pemeliharaan dan rehabilitasi serta memperlebar lahan badan jalan. Dengan adanya rencana tersebut diharapkan dapat mengurangi permasalahan-permasalahan di atas.

\section{B. METHOD}

Metode penelitian yang digunakan adalah dengan menganalisa pembebanan jaringan pada sistem jaringan jalan di wilayah studi dengan menggunakan bantuan software Vissim. Penelitian ini terbatas pada analisis sistem lalu lintas di kawasan pintu masuk Nagoya (Jalan Bunga Raya-Raden Patah), sehingga perlu dilakukan manajemen dan rekayasa lalu lintas terhadap ruas jalan dan persimpangan di kawasan tersebut. Analisis tersebut berdasarkan perhitungan volume lalu lintas di wilayah studi. Selain itu bertujuan mengkaji kinerja lalu lintas berdasarkan indikator kecepatan, kepadatan, tundaan, dan dan V/C ratio. Pengumpulan data ini meliputi data primer dan data sekunder. Data primer meliputi data inventarisasi ruas, data inventarisasi simpang, data volume lalu lintas, data kecepatan kendaraan, data waktu tempuh kendaraan. Sedangkan data sekunder meliputi peta jaringan jalan dan peta tata guna lahan. Setelah dilakukan pengumpulan data, maka dari data yang telah dikumpulkan selanjutnya dilakukan analisis untuk mendapatkan kondisi eksisting dari wilayah studi.

\section{HASIL DAN PEMBAHASAN}

\section{Kinerja Kondisi eksisting}

Penilaian kinerja ruas jalan pada wilayah studi penelitian ruas Jalan Bunga Raya-Raden Patah menggunakan beberapa indikator sebagai berikut: 
a) Kapasitas Ruas Jalan

Dalam menghitung kapasitas jalan diperlukan data tipe jalan, hambatan samping, tata guna lahan, persentase arus lalu lintas per arah, lebar efektif jalan dan jumlah penduduk yang diperoleh dari survei inventarisasi jalan. Contoh dalam penghitungan kapasitas jalan sebagai berikut:

Diketahui dari survei inventarisasi Jalan Bunga Raya 1, memiliki tipe jalan 4/2 D, dengan lebar efektif jalan $12 \mathrm{~m}$, dengan tata guna lahan komersial dan hambatan samping sedang, prosentase arus lalu lintas perarah adalah 50\%:50\% dan diketahui data sekunder penduduk Kota Batam 1.329.773 jiwa. Dengan melihat tabel koreksi pada Manual Kapasitas Jalan Indonesia (MKJI) 1997. Dari hasil penelitian ruas jalan yang ada pada Jalan Bunga RayaRaden Patah dapat dilihat bahwa kapasitas tiap ruas jalan di wilayah studi penelitian memiliki perbedaan baik dipengaruhi oleh kapasitas dasar, hambatan samping, dan beberapa faktor lain yang mempengaruhinya. Kapasitas terbesar terdapat pada Jalan Sudirman 1 dengan kapasitas sebesar 4752.

b) Volume Lalu Lintas

Berdasarkan hasil pengamatan terlihat bahwa ruas jalan memiliki volume lalu lintas terbesar adalah jalan Bunga Raya 1 dengan volume sebesar 2467,51 smp/jam. Sedangkan pada wilayah studi penelitian ruas jalan yang memiliki volume lalu lintas terkecil adalah ruas Jalan Pembangunan dengan volume sebesar 1187,84 smp/jam.

c) V/C Ratio

Berdasarkan hasil pengukuran terlihat bahwa ruas jalan memiliki volume lalu lintas terbesar adalah jalan Bunga Raya 1 dengan volume sebesar 2467,51 smp/jam. Sedangkan pada wilayah studi penelitian ruas jalan yang memiliki volume lalu lintas terkecil adalah ruas Jalan Pembangunan dengan volume sebesar 1187,84 smp/jam.

d) Kecepatan Ruas Jalan

Berdasarkan hasil pengukuran terlihat bahwa ruas jalan yang memiliki kecepatan ratarata tertinggi yaitu ruas Jalan Sudirman 1 sebesar 54,45 km/jam. Sedangakan ruas jalan yang memiliki kecepatan rata-rata terendah yaitu ruas Jalan Bunga Raya 1 sebesar 30,31 km/jam.

e) Kepadatan Ruas jalan

Kepadatan ruas jalan dapat dihitung dengan cara volume lalu lintas hasil survei pencacahan lalu lintas yang sudah dikonversikan dalam satuan mobil penumpang dikali waktu perjalanan hasil survei pengamatan kendaraan bergerak dan dibagi panjang jalan.

f) Tingkat pelayanan Jalan

Tingkat pelayanan dan kinerja ruas jalan diukur dengan cara melihat kinerja ruas jalan. Dalam menentukan tingkat pelayanan ruas jalan pada ruas ruas Jalan Bunga Raya-Raden Patah berdasarkan Peraturan Menteri Nomor 96 Tahun 2015. Berdasarkan hasil penelitian terlihat bahwa tingkat pelayanan ruas jalan bervariasi. Tingkat pelayanan terbawah terdapat pada ruas jalan Bunga Raya 1 dengan V/C Ratio 0,69 dengan kecepatan 30,31 km/jam. Tingkat pelayanan teratas terdapat pada ruas jalan Sudirman 1 dengan V/C Ratio 0,32 dengan kecepatan $54,45 \mathrm{~km} / \mathrm{jam}$.

g) Pembebanan Lalu Lintas

Tahapan pembebanan lalu lintas yang dilakukan yakni dengan menggunakan software vissim yang mana hasil yang didapatkan seperti kinerja ruas dan jaringan jalan serta dilengkapi dengan visualisasi. Adapun pembebanan lalu lintas tersebut didapatkan dari hasil dilapangan (survei) yang nantinya di bandingkan dengan model. Dari data didapatkan bahwa kinerja ruas jalan kondisi eksisiting memiliki volume tertinggi adalah ruas Jalan Bunga Raya 1 dengan volume sebesar 5559 kendaraan/jam pada jalan Bunga Raya-Raden Patah Kota Batam. Setelah didapatkan permodelan pembebanan ruas jalan lalu lintas pada tahun 2019, secara makro dapat diketahui pula kinerja lalu lintas pada jalan Bunga Raya-Raden Patah Kota Batam.

h) Validasi Model Jaringan Jalan 
Permodelan lalu lintas pada tahap analisis pembebanan lalu lintas diatas menggunakan bantuan software Vissim. Sebelum model lalu lintas tersebut digunakan untuk melakukan analisis lebih lanjut, maka dilakukan validasi terhadap model tersebut. Validasi model dimaksudkan untuk menguji apakah hasil model yang didapatkan mempunyai perbedaan yang cukup signifikan dengan hasil survei lalu lintas di lapangan. Apabila tidak terdapat perbedaan yang cukup signifikan maka hasil model data diterima. Sebaliknya, apabila terdapat perbedaan yang signifikan, maka hasil model tidak dapat diterima. Sehingga model tersebut dapat mempresentasikan lalu lintas sesuai dengan keadaan sebenarnya di lapangan. Validasi model dilakukan berdasarkan hasil tes chi-kuadrat antara hasil model dengan hasil survei lalu lintas di lapangan.

\section{Pengaturan Lalu Lintas dengan Beberapa Alternatif Kebijakan}

a) Kebijakan Yang Sudah Ada

Kebijakan Larangan Fasilitas berputar Balik dimana Kebijakan ini untuk mengatasi tundaan yang di sebabkan kendaraan yang berputar arah di simpang. Apabila arus ruas yang berlawanan arah sangat padat, maka tundaan yang terjadi sangat besar sekali. Biasanya saat kendaraan berputar balik akan terjadi konflik dengan kendaraan yang berlawanan.Kebijakan Simpang dengan APILL dimana Terdapat 2 Simpang ber-APILL yang terdapat pada Jalan Bunga Raya-Raden Patah yaitu Simpang Indomobil (3 fase) dan Simpang Baloi (3 fase). Kebijakan Simpang prioritas yang mana terdapat Terdapat 2 Simpang ber-APILL yang terdapat pada Jalan Bunga Raya-Raden Patah yaitu Simpang Indomobil (3 fase) dan Simpang Baloi (3 fase).

b) Strategi Pengaturan Lalu Lintas Pada Jalan Bunga Raya-Raden Patah Kota Batam Kondisi Eksisting Saat Ini (Do Something) Tahun 2019.

Dari hasil analisis yang telah dilakukan terhadap studi yang dilakukan pada Jalan Bunga Raya-Raden Patah Kota Batam, permasalahan yang muncul dalam wilayah penelitian ini adalah terkait dengan tingkat pelayanan ruas jalan. Hal tersebut dipengaruhi oleh beberapa parameter utama yang mengidentifikasikan bahwa tingkat pelayanan tersebut. Parameter tersebut diantaranya adalah VC ratio, kecepatan, dan kepadatan. Tujuan diadakan pengaturan lalu lintas ini diharapkan agar dapat meningkatkan pelayanan lalu lintas yang baik bagi pengguna jalan khususnya menuju ke kawasan CBD Kota Batam. Berikut ini adalah beberapa kegiatan alternatif yang dapat digunakan untuk meningkatkan kinerja ruas menuju kawasan CBD Pada Jalan Bunga Raya-Raden Patah Kota Batam.

1) Skenario Pertama

Merupakan skenario peningkatan kinerja lalu lintas dengan cara melakukan peningkatan geometri jalan dengan menambahkan 1 lajur permasing-masing ruas dan perbaikan siklus waktu apill pada simpang. Dapat diketahui bahwa kinerja ruas jalan pada wilayah penelitian pada beberapa ruas jalan mengalami peningkatan setelah skenario diterapkan walaupun hanya sebagian kecil ruas jalan yang mengalami peningkatan. Pada tabel tersebut, persentase yang ditampilkan merupakan kondisi skenario yang mengalami peningkatan dari kondisi eksisting dan atau sebaliknya. Hal tersebut dapat dilihat dari ve ratio yang berkurang dan kecepatan pada ruas jalan telah mengalami peningkatan.

Setelah dilakukan skenario pertama perubahan terjadi pada Simpang Indomobil dan Baloi. Untuk hasil persentase yang positif mengalami peningkatan sedangkan negatif mengalami penurunan. Pada skenario 1, terjadinya penurunan antrian dan tundaan dari hasil kinerja simpang. Pada simpang Indomobil terlihat berkurangnya antrian sebanyak $62 \%$ dari 100,21 meter menjadi 38,03 meter, serta mengalami penuruan tundaan sebanyak $67 \%$ dari 45 detik menjadi 15 detik.

Untuk kinerja jaringan jalan pada pintu masuk Nagoya setelah di terapkan skenario 1 dengan melakukan peningkatan kapasitas di ruas serta memperbaiki waktu siklus apill terjadi 
peningkatan pada jaringan jalan di pintu masuk kawasan Nagoya. Untuk hasil persentase yang positif mengalami peningkatan sedangkan negatif mengalami penurunan, terlihat dari tundaan rata-rata mengalami penuruan sebanyak $84 \%$ menjadi 17 detik, kecepatan jaringan meningkat $24 \%$ menjadi $46,08 \mathrm{~km} / \mathrm{jam}$, total jarak perjalanan $12,98 \mathrm{~km}$ dan total waktu perjalanan menurun $19 \%$ menjadi 1.014 detik.

2) Skenario Kedua

Dalam melakukan analisis pengendalian simpang, tipe simpang yang akan dibuat harus memperhatikan hubungan antara volume lalu lintas mayor dan minor. Penentuan pengaturan persimpang dengan membandingkan lalu lintas kendaraan/hari antara jalan mayor dan minor. Berdasarkan hasil analisis, simpang polsek lubuk baja memiliki volume 16.985 kendaraan/hari di jalan mayor dan 5.144 kendaraan/hari (Pola Umum Kota Batam 2019). Maka menunjukkan pengaturan persimpangan pada simpang polsek lubuk baja masih dalam bentuk simpang prioritas.

Skenario kedua (S2) adalah melakukan perekayasaan berupa menjadikan simpang prioritas pada pertemuan jalan antara Bunga Raya 1 dan Raden Patah dengan membuka median di ruas Bunga Raya 1, penutupan putar balik di ruas Yos Sudarso 1 dan Bunga Raya 1 serta merubah fase apill pada simpang baloi dengan siklus apill yang tetap. dapat diketahui bahwa kinerja ruas jalan pada skenario 2 (S2) mengalami perubahan. Berdasarkan tabel tersebut persentase yang menunjukkan hasilnya positif, mengalami peningkatan dari kondisi eksisting dan atau sebaliknya. Jalan Pembangunan memiliki perbedaan yang siginifikan dengan kondisi yang eksisting dengan VC Ratio mengalami penurunan 34\% dari 0,44 menjadi 0,29 dengan kecepatan naik $17 \%$ yang sebelumnya $45,32 \mathrm{~km} / \mathrm{jam}$ menjadi $52,81 \mathrm{~km} / \mathrm{jam}$.

Setelah dilakukan skenario kedua kinerja simpang mengalami penurunan pada Simpang Polsek Lubuk Baja dari tingkat pelayanan A menjadi pelayanan E. Berdasarkan hasil penelitian persentase yang menunjukkan hasilnya positif, mengalami peningkatan dari kondisi eksisting dan atau sebaliknya. Adapun kinerja jaringan jalan pintu masuk Nagoya yang berada pada Jalan Bunga Raya-Raden Patah setelah dilakukan penerapan skenario 2 dapat dilihat persentase yang ditampilkan bernilai positif mengalami peningkatan sedangkan negatif mengalami penurunan. Pengendalian pada skenario 2 adalah pengendalian simpang prioritas di simpang polsek lubuk baja serta merubah fase apill di simpang baloi menjadi 4 fase terlihat tundaan rata-rata mengalami penurunan 39\% menjadi 66 detik, kecepatan jaringan menurun menjadi 36,38 $\mathrm{km} / \mathrm{jam}$, total jarak perjalanan 11,92 km dengan total waktu perjalanan menjadi 1.180 detik.

3) Skenario Ketiga

Skenario ketiga (S3) dengan menggabungkan skenario 1 dan 2 yaitu peningkatan kapasitas ruas dengan cara melakukan peningkatan geometri jalan dengan menambahkan 1 lajur permasing-masing ruas, memperbaiki waktu apill, merubah fase apill di simpang baloi menjadi 4 fase, melakukan perekayasaan berupa menjadikan simpang prioritas pada pertemuan jalan antara Bunga Raya 1 dan Raden Patah dengan membuka median di ruas Bunga Raya 1, penutupan putar balik di ruas Yos Sudarso 1 dan Bunga Raya.

Berdasarkan hasil penelitian persentase yang ditampilkan menunjukkan tentang adanya peningkatan dan penurunan skenario terhadap kondisi eksisting, dapat diketahui bahwa kinerja ruas jalan pada pintu masuk kawasan Nagoya naik secara signifikan. Hal tersebut dapat dilihat dari VC Ratio yang naik rata-rata $40 \%$ dari kondisi eksisting. Setelah dilakukan skenario ketiga terjadi perubahan pada semua simpang contohnya Simpang Indomobil dari tingkat pelayanan C menjadi tingkat pelayanan A serta Simpang Baloi dari tingkat pelayanan D menjadi B. Pada tabel tersebut persentase yang ditampilkan menunjukkan tentang adanya peningkatan dan penurunan skenario terhadap kondisi eksisting. Diketahui juga bahwa antrian yang sebelumnya sebesar 100,21 meter menjadi 45,86 meter yang mengalami penuruan 54\% dan tundaan 45 detik menjadi 14 detik dengan mengalami penurunan $69 \%$. 
Selain itu setelah dilakukan skenario ketiga terjadi peningkatan pada jaringan jalan tersebut. Persentase yang ditampilkan menunjukkan tentang adanya peningkatan dan penurunan skenario terhadap kondisi eksisting. Hasil dari skenario 3 mendapatkan tundaan rata-rata yang mengalami penurunan hingga $81 \%$ menjadi 21 detik, kecepatan $44,78 \mathrm{~km} / \mathrm{jam}$, total jarak perjalanan $12 \mathrm{~km}$ dengan total waktu perjalanan menjadi 964 detik.

\section{Rekomendasi Usulan Dan Implementasi Skenario}

Didalam pemilihan alternatif terbaik dilakukan pembobotan terhadap parameter kinerja jaringan setelah dibandingkan antara kondisi eksisting, skenario 1, skenario 2, dan skenario 3. Berikut akan ditampilkan hasil pembobotan nilai kinerja jaringan pada Tabel 1

\section{Tabel 1 Pembobotan Nilai Kinerja Jaringan}

\begin{tabular}{|c|c|c|c|c|c|c|c|c|c|c|c|c|c|}
\hline Skenario & $\begin{array}{c}\text { Tundaan } \\
\text { (detik) }\end{array}$ & $\begin{array}{c}\text { Perse } \\
\text { ntase }\end{array}$ & $\mathbf{n}$ & $\begin{array}{c}\text { Kecepatan } \\
\mathbf{( k m / j a m )}\end{array}$ & $\begin{array}{c}\text { Perse } \\
\text { ntase }\end{array}$ & $\mathbf{n}$ & $\begin{array}{c}\text { Jarak } \\
\text { Perjalanan } \\
\mathbf{( k m )}\end{array}$ & $\begin{array}{c}\text { Perse } \\
\text { ntase }\end{array}$ & $\mathbf{n}$ & $\begin{array}{c}\text { Waktu } \\
\text { Perjalanan } \\
\text { (detik) }\end{array}$ & $\begin{array}{c}\text { Perse } \\
\text { ntase }\end{array}$ & $\mathbf{n}$ & $\sum \mathbf{n}$ \\
\hline Eksisting & 109 & - & & 37 & - & & 12,90 & - & & 1.254 & - & & \\
\hline S1 & 17 & $-84 \%$ & 3 & 46 & $24 \%$ & 3 & 12,98 & $1 \%$ & 1 & 1.014 & $-19 \%$ & 2 & 9 \\
\hline S2 & 66 & $-39 \%$ & 1 & 36 & $-3 \%$ & 1 & 11,92 & $-8 \%$ & 3 & 1.180 & $-6 \%$ & 1 & 6 \\
\hline S3 & 21 & $-81 \%$ & 2 & 45 & $22 \%$ & 2 & 12 & $-7 \%$ & 2 & 964 & $-23 \%$ & 3 & 9 \\
\hline
\end{tabular}

Sumber: Hasil Analisis, 2020

Berdasarkan Tabel 1 dapat diambil kesimpulan bahwa tahap penanganan skenario 1 dan 3 memiliki jumlah nilai pembobotan yang sama sehingga dijadikan rekomendasi penanganan jika dilihat dari kinerja jaringan jalan. Tetapi hasil penanganan dari setiap skenario berbeda. Skenario pertama digunakan jika lebih memprioritaskan kecepatan perjalanan sedangkan skenario ketiga cenderung memperhatikan waktu perjalanan. Usulan tersebut akan dijadikan referensi oleh pihak terkait dari segi parameter yang akan digunakan.

\section{KESIMPULAN}

Perekayasaan lalu lintas pada saat kondisi eksisting menggunakan tiga skenario. Skenario 1 yaitu melakukan peningkatan kapasitas ruas dan perbaikan waktu apill di simpang indomobil dan simpang baloi. Skenario 2 adalah melakukan perekayasaan berupa menjadikan simpang prioritas pada pertemuan jalan antara Bunga Raya 1 dan Raden Patah dengan membuka median di ruas Bunga Raya 1, penutupan putar balik di ruas Yos Sudarso 1 dan Bunga Raya 1 serta merubah fase apill pada simpang baloi dengan siklus apill yang tetap. Skenario 3 yaitu dengan menggabungkan skenario 1 dan 2 yaitu melakukan peningkatan kapasitas ruas, perbaikan waktu apill di simpang indomobil dan simpang baloi, menutup fasilitas putar balik arah di ruas yos sudarso 1 dan bunga raya 1 , perekayasaan simpang prioritas di simpang polsek lubuk baja dengan membuka median pada ruas Bunga Raya 1 serta merubah fase apill di simpang baloi.

Berdasarkan hasil analisis, rekomendasi usulan dalam penanganan lalu lintas pada Jalan Bunga Raya-Raden Patah kota Batam adalah dengan menerapkan skenario satu dan skenario 3. Diperlukan penanganan dan fasilitas penunjang setelah diterapkannya pengaturan lalu lintas, antara lain: a. Peningkatan kapasitas ruas yang dilakukan dengan meningkatkan geometri jalan dengan menambah 1 Lajur pada masing-masing ruas; b. Perbaikan siklus waktu apill pada simpang indomobil dan simpang baloi; c. Perubahan fase apill pada simpang baloi; d. 
Membuka median pada simpang polsek lubuk baja menjadi simpang prioritas, serta menutup fasilitas putar balik arah di ruas yos sudarso 1 dan bunga raya 1 .

\section{DAFTAR PUSTAKA}

Aryandi, R.D. 2014. Penggunaan Software Vissim Untuk Analisis Simpang Bersinyal (Studi Kasus Simpang Mirota Kampus Terban Yogyakarta). The 17th FSTPT International Symposium. Jember: Universitas Jember.

Diana W. 2014. Chi Square Dan Uji Persyaratan Analisis. Makalah Statistika. Malang: Universitas Negeri Malang.

https://id.wikipedia.org/wiki/Kota_Batam. Kota Batam. Diakses Pukul 15.06 Pada Tanggal 14 April 2020.

Meiliasari, S.K. 2018. Manajemen Rekayasa Lalu Lintas Pada Kawasan Pasar Jelojok Kopang Kabupaten Lombok Tengah. Skripsi DIV Transportasi Darat Sekolah Tinggi Transportasi Darat. Bekasi: STTD.

Peraturan Daerah Kota Batam Nomor 8 Tahun 2016 tentang Rencana Pembangunan Jangka Menegah Daerah (RPJMD) Kota Batam Tahun 2016-2021. Batam: Pemerintah Kota Batam.

Peraturan Darah Kota Batam Nomor 9 Tahun 2001 tentang Lalu Lintas dan Angkutan Jalan di Kota Batam. Batam: Pemerintah Kota Batam.

Peraturan Menteri Nomor 96 Tahun 2015 tentang Pedoman Pelaksanaan Kegiatan Manajemen dan Rekayasa Lalu Lintas. Jakarta: Kementrian Perhubungan RI.

Peraturan Pemerintah Nomor 32 Tahun 2011 tentang Manajemen dan Rekayasa, Analisis Dampak, Serta Manajemen Kebutuhan Lalu Lintas. Jakarta: Kementrian Perhubungan RI.

Peraturan Pemerintah Nomor 62 Tahun 2019 tentang Kawasan Perdagangan Bebas dan Pelabuhan Bebas Batam. Jakarta: Kementrian Perhubungan RI.

Prajawati K. 2017. Manajemen Rekayasa Lalu Lintas Pada Kawasan Pasar Ketanggunangan Kabupaten Brebes. Skripsi DIV Transportasi Darat Sekolah Tinggi Transportasi Darat. Bekasi: STTD.

Prakarsa J. 2018. Kebijakan Pemerintah Daerah Dalam Rekayasa Lalu Lintas Di Kota Bandar Lampung. Skripsi Hukum Administrasi Negara. Bandar Lampung: Universitas Lampung.

Rencana Strategis Tahun 2016-2021. Batam: Badan Perencanaan dan Penelitian Pengembangan Pembangunan Daerah Kota Batam (Bapelitbangda).

Undang-Undang Nomor 22 Tahun 2009 tentang Lalu Lintas Angkutan Jalan. Jakarta: Direktorat Jenderal Perhubungan Darat.

Yulistiyanti, L.D. 2016. Manajemen Dan Rekayasa Lalu Pada Ruas Jalan Mohammad Hatta M.Yamin Di Kota Solok. Skripsi DIV Transportasi Darat Sekolah Tinggi Transportasi Darat. Bekasi: STTD. 